\title{
Energy performance of low temperature heating systems in five new- built Swedish dwellings: A case study using simulations and on-site measurements
}

\author{
Arefeh Hesaraki*, Sture Holmberg \\ Division of Fluid and Climate Technology, School of Architecture and the Built Environment, KTH Royal Institute of Technology, Brinellvägen 23, 10044 \\ Stockholm, Sweden
}

\section{A R T I C L E I N F O}

\section{Article history:}

Received 30 October 2012

Received in revised form

12 February 2013

Accepted 13 February 2013

\section{Keywords:}

Low temperature hydronic heating system

Energy performance

IDA ICE 4

Site measurements

\begin{abstract}
A B S T R A C T
In Europe, high energy consumption in built environments has raised the need for developing low energy heating systems both in new building and in retrofitting of existing buildings. This paper aims to contribute by presenting annual results of calculated and measured energy consumption in five newbuilt semi-detached dwellings in Stockholm, Sweden. All buildings were equipped with similar low temperature heating systems combining under-floor heating and ventilation radiators. Exhaust ventilation heat pumps supported the low temperature heating system. Buildings were modeled using the energy simulation tool IDA Indoor Climate and Energy (ICE) 4, and energy consumption of the heat pumps was measured. Results showed that calculated and measured results were generally in agreement for all five dwellings, and that the buildings not only met energy requirements of the Swedish building regulations but also provided good thermal comfort.
\end{abstract}

(ㄷ) 2013 Elsevier Ltd. All rights reserved.

\section{Introduction}

Energy consumption in European buildings accounts for $40 \%$ of total primary energy usage [1], and energy required for heating is responsible for most of this, i.e. more than $70 \%$ [2]. In the building sector there is a considerable potential for saving energy, such as by using materials with low heat transfer coefficient (low $U$ value), tight building envelopes or using energy-saving equipment in heat recovery from exhaust air, such as heat exchangers or exhaust air heat pumps. All these measures can lead to reducing the duration of the heating season and thus the total space heating load. In low energy buildings, the low temperature heating system usually works with a supply water temperature below $45^{\circ} \mathrm{C}$.

The number of heat pumps used as a heating source in Sweden has increased widely during recent decades. Myhren and Holmberg [3] showed that a combination of LTHH system and heat pump was more thermally efficient compared to a high temperature heating system. As a rule of thumb, the coefficient of performance (COP) of a heat pump improves by $1-2 \%$ for every degree reduction in supply water temperature [4]. The lower the supply temperature, the higher the COP and the more energy efficient and sustainable is

\footnotetext{
* Corresponding author. Tel.: +46 879048 84; fax: +46 87904800.

E-mail addresses: arefeh.hesaraki@byv.kth.se, arefeh@kth.se (A. Hesaraki).
}

the system thus created. In addition, LTHH systems are not only energy efficient, but also exergy efficient and environmental friendly [5].

Using an LTHH system increases not only energy efficiency but also thermal comfort [6-8]. Three common types of LTHH systems are under-floor heating (UFH), wall heating and ceiling heating. All are able to work with low supply water temperature due to a large heat transmitting surface area. Another less well-known type of LTHH system is the ventilation radiator, which due to high convection heat transfer can work with low supply water temperature. The ventilation radiator [9] (Fig. 1) is a combination of ventilator and radiator. The supply air vent is located on the wall behind the radiator and is connected to the radiator through a channel. In this combined system, cold fresh air is forced to pass through the radiator panels, due to buoyancy forces and a constant underpressure in the building, created by exhaust fans. Hence, the air is preheated before entering the building.

The performance of the ventilation radiators has been laboratory tested [9]. Measurements have shown that the ventilation radiators have potential to raise the temperature of cold air by up to $30{ }^{\circ} \mathrm{C}$ or more in winter time. The critical factor in using a combination of ventilation radiators and mechanical ventilation is the airtightness of building [9] with respect to the efficiency of radiator and total energy consumption. In other words, a high infiltration rate will lead to an increase in the non-preheated air that does not 


\begin{tabular}{|c|c|c|c|}
\hline \multicolumn{2}{|c|}{ Nomenclature } & \multirow{2}{*}{$\begin{array}{l}\text { NCC } \\
\text { NMF }\end{array}$} & \multirow{2}{*}{$\begin{array}{l}\text { a leading construction and property development } \\
\text { company in the Nordic region } \\
\text { neutral model format }\end{array}$} \\
\hline $\mathrm{ACH}$ & air change per hour & & \\
\hline AHU & air handling unit & PMV & predicted mean vote \\
\hline & Planning & $P_{\text {vap }}$ & partial water vapour pressure $(\mathrm{Pa})$ \\
\hline BES & building energy simulation & $Q_{\mathrm{cv}}$ & convective heat load from occupants (W) \\
\hline CAV & constant air volume & $Q_{\text {radocc }}$ & radiative heat load from the occupants (W) \\
\hline DHW & domestic hot water & SHGC & solar heat gain coefficient \\
\hline$f_{\mathrm{cl}}$ & $\begin{array}{l}\text { ratio of man's surface area while clothed to man's } \\
\text { surface area while unclothed }\end{array}$ & $\begin{array}{l}\text { SMHI } \\
t_{\text {air }}\end{array}$ & $\begin{array}{l}\text { Sweden's Meteorological and Hydrological Institute } \\
\text { air temperatures }\left({ }^{\circ} \mathrm{C}\right)\end{array}$ \\
\hline$h_{\mathrm{cl}}$ & $\begin{array}{l}\text { convective heat transfer coefficient between air and } \\
\text { clothes }\left(\mathrm{W} \mathrm{m} \mathrm{m}^{-2} \mathrm{~K}^{-1}\right)\end{array}$ & $\begin{array}{l}t_{\mathrm{cl}} \\
t_{\mathrm{mrt}}\end{array}$ & $\begin{array}{l}\text { surface temperature of clothing }\left({ }^{\circ} \mathrm{C}\right) \\
\text { mean radiant temperature }\left({ }^{\circ} \mathrm{C}\right)\end{array}$ \\
\hline HumOcc & humidity load from occupants $\left(\mathrm{kg} \mathrm{s}^{-1}\right)$ & UFH & under-floor heating \\
\hline ISO & International Organization for Standardization & VR & ventilation radiator \\
\hline ITM & Swedish Institute of Applied Mathematics & $W$ & external work $\left(\mathrm{W} \mathrm{m}^{-2}\right)$ \\
\hline $\begin{array}{l}\text { LTHH } \\
M\end{array}$ & $\begin{array}{l}\text { low temperature hydronic heating } \\
\text { metabolic rate (MET) }\end{array}$ & WC & water closet \\
\hline
\end{tabular}

pass through the radiator, causing additional need for space heating. The airtightness of the building during test condition is usually measured at a reference pressure of 50 Pa difference between inside and outside. A suitably high pressure, such as $50 \mathrm{~Pa}$, is chosen not only so as to minimize the effects of stack-induced and winddriven air flow, but also so as to be able to compare different buildings at the same reference value. This factor is especially important when retrofitting existing buildings with ventilation radiators.

One of many positive qualities of ventilation radiators is enhancement of forced convection by blowing cold air between the radiator's panels, allowing reduction of supply water temperature to the radiator without sacrificing heat output. Convective heat transfer is not only increased by high air velocity of incoming air, but also by the great temperature difference between cold incoming air and the heating unit. A previous study [9] showed that higher air velocity and greater temperature difference produced increased heat output in the radiators as a result of heat transfer enhancement. In addition, both a theoretical study [10] and

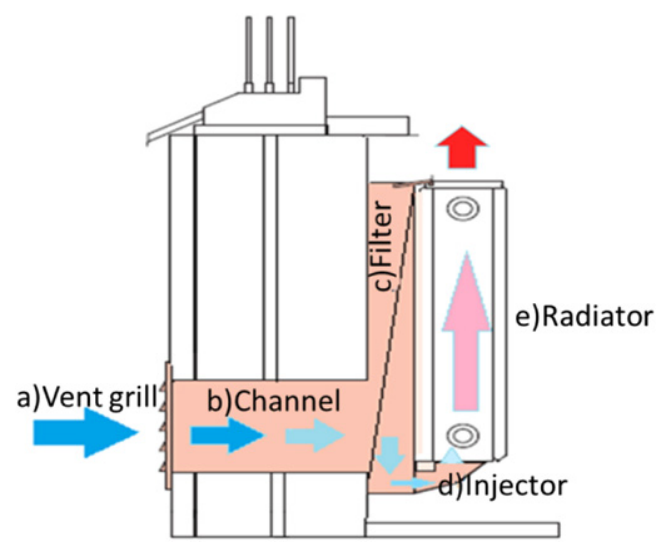

Fig. 1. Main parts of a ventilation radiator: (a) Vent grill on the external wall, (b) Channel through wall, (c) Filter, (d) Injector or inlet (with or without mixing of cold supply air with room air), (e) Traditional radiator [9]. laboratory measurements [9] have shown that working with the same supply water temperature, the integration of heating components (baseboards, radiators) with ventilation function leads to increased heat output from the heating system in comparison to conventional system. The combined heating and ventilation system gave twice the heat output per unit length compared to traditional radiator system due to increasing convection heat transfer. Furthermore, laboratory measurements [9] showed that a ventilation radiator working with $35^{\circ} \mathrm{C}$ supply water temperature had the same heat output as a traditional radiator working with a supply water temperature of $55^{\circ} \mathrm{C}$.

Previous studies [5,9-11] focused on developing the ventilation radiator in the laboratory and on modeling by CFD (Computational Fluid Dynamics), with the question of how it functions in reality still to be addressed. According to the authors' knowledge there are no published studies that report the energy performance of a building with ventilation radiator. All previous studies are limited to modeling with CFD and analytical model, and no study report how the ventilation radiator functions in reality, or whether buildings equipped with ventilation radiators are following the Swedish building regulations. Previous laboratory measurements and simulations, however, led to the hope that this kind of radiator could be an energy-saving system. To evaluate its energy performance and thermal comfort in reality, five semi-detached buildings (Fig. 2) equipped with ventilation radiators were chosen. A detailed comparison of the measured and calculated electricity consumption for heating and ventilation (by heat pump and fan) in the five semi-detached houses was then made, from 14th December 2011 to 13th December 2012. The calculation of energy requirements was made using the building energy simulation (BES) tool IDA Indoor Climate and Energy (ICE) 4, hereafter called IDA ICE 4.

\section{Description of the case study buildings}

\subsection{Building dimensions and construction}

Five semi-detached, new-built dwellings in Stockholm were selected for both measurements and simulation. These five had responded positively to our request for reporting on the heat pump 


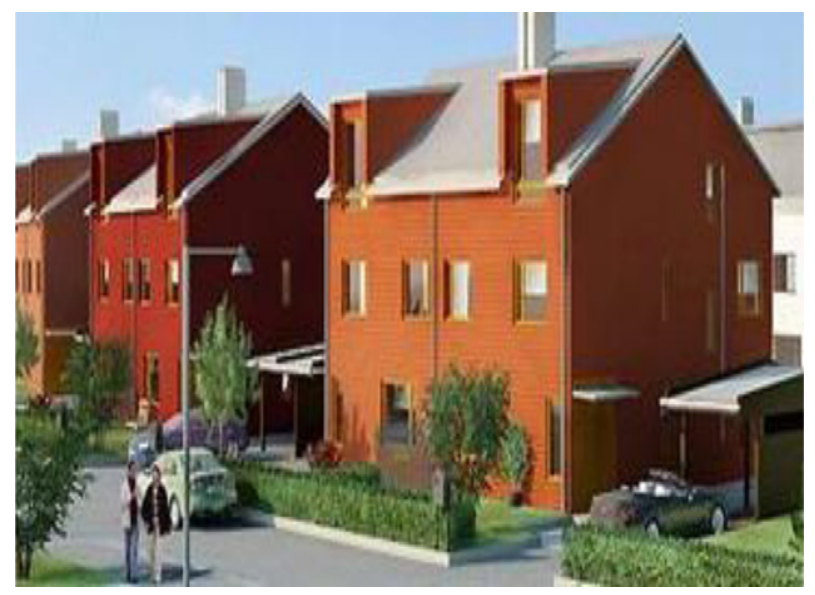

Fig. 2. Some of the semi-detached houses in Stockholm that were selected for study

electricity consumption. The dwellings were numbered 27, 30, 31, 32 and 33. The geometry of all houses was the same but compass orientation differed. They each had three stories with total floor area of $160 \mathrm{~m}^{2}$ including kitchen, bathrooms, living room and bedrooms. The floor plan and installed ventilation system for a typical dwelling are presented in Fig. 3. $U$ values for different parts of the building envelope are presented in Table 1 . The average $U$ value was $0.28 \mathrm{~W} \mathrm{~m}^{-2} \mathrm{~K}^{-1}$, significantly lower than the limited mean value assigned by the Swedish building regulations (BBR) [12], i.e. $0.5 \mathrm{~W} \mathrm{~m} \mathrm{~m}^{-2} \mathrm{~K}^{-1}$. For the glazing, the solar heat gain coefficient (SHGC) was 0.5. This represented half of incident solar radiation admitted through a window and released inward, both by directly transmitted and absorbed radiation.

\subsection{HVAC (heating, ventilation and air conditioning) system}

\subsubsection{Heating system}

The heating systems in the buildings studied were all the same, i.e. hydronic low temperature systems that included under-floor heating for the first floor, and ventilation radiators for the second and third floors, (Fig. 4). In addition, bathroom had electrical underfloor heating. The actual temperatures of supply and return flows from radiators were $45^{\circ} \mathrm{C}$ and $30^{\circ} \mathrm{C}$ respectively. Return flow from the radiators was supplied to the under-floor heating. The heat source for both space heating load and domestic hot water (DHW) production was an exhaust air heat pump that extracted the heat from exhaust air to heat water (air-water source). As can be seen in Fig. 4, the heat pump is also equipped with electrical auxiliary heater of $4.0 \mathrm{~kW}$ that is used when instantaneous hot water is needed. The exhaust air heat pump used in the test buildings was ComfortZone CE50. This heat pump has a variable compressor speed, which is able to adjust flow temperature to heating demand so as to maintain indoor air temperature around a suitable level of $21{ }^{\circ} \mathrm{C}$. However, since the heat pump was placed in the bathroom, where temperature is often higher than in other rooms, an incorrect indication of mean indoor temperature was possible. The average coefficient of performance (COP) of an exhaust air heat pump producing hot water at $50{ }^{\circ} \mathrm{C}$ is 2.7 [13].

\subsubsection{Ventilation and infiltration}

In the exhaust ventilation system, polluted air was extracted from exhaust devices placed in kitchen, bathroom and wardrobes at a constant air volume (CAV) of $60 \mathrm{l} \mathrm{s}^{-1}$ for $24 \mathrm{~h} \cdot \mathrm{day}^{-1}$. Exhausted air was replaced by fresh outdoor air entering through inlets in bedrooms and living room due to a 10 Pa constant under-pressure in the building. The inlet for fresh supply air was placed above the windows of the first floor, and cold air was brought into the house without preheating. However, for the second and third floors the cold air was preheated by ventilation radiators. The total exhaust air flow rate was $601 \mathrm{~s}^{-1}$, i.e. $10 \mathrm{l} \mathrm{s}^{-1}$ extracted from kitchen, $26 \mathrm{l} \mathrm{s}^{-1}$ from bathroom and WC, $61 \mathrm{~s}^{-1}$ from wardrobes and $181 \mathrm{~s}^{-1}$ from third floor. The total air flow rate was $0.375 \mathrm{l} \mathrm{s}^{-1} \mathrm{~m}^{-2}$ of floor area, fulfilling the minimum requirement [12] for residential buildings, i.e. $0.350 \mathrm{~s}^{-1} \mathrm{~m}^{-2}$ of floor area. In the buildings studied, the blower door test showed that air leakage was $0.63 \mathrm{l} \mathrm{s}^{-1} \mathrm{~m}^{-2}$ of external surface under 50 Pa pressure difference. This showed a good airtightness relative to $0.80 \mathrm{~s} \mathrm{~s}^{-1} \mathrm{~m}^{-2}$ requirements for Swedish houses.

\subsection{Weather conditions}

The buildings studied are located in Stockholm with average daily temperature of $6.6^{\circ} \mathrm{C}$. The weather data was given by Swedish Meteorological and Hydrological Institute (SMHI) for the Stockholm region where the tested buildings were located. The coldest temperature was $-28.8^{\circ} \mathrm{C}$ on 23 rd February 2012 and the warmest temperature was $27.5^{\circ} \mathrm{C}$ on 2nd July 2012 .

\section{Methods}

\subsection{IDA ICE 4}

Simulation programs are often used nowadays to predict and analyze the performance of buildings and HVAC systems. IDA ICE 4 [14] is a dynamic simulation tool providing simultaneous dynamic simulation of heat transfer and air flow by creating a mathematical model [15] to calculate the heating and cooling load in a building, and predict the thermal comfort and indoor air quality based on building properties defined by the user. IDA ICE 4 was initially developed at KTH Royal Institute of Technology and the Swedish Institute of Applied Mathematics, ITM. The first version of the model library of IDA ICE 4 was written in neutral model format (NMF) within IEA Task 22. NMF [16] is a program independent language using differential algebraic equations for modeling the dynamic systems. In IDA ICE 4, the mathematical library is modeled with the equations from ISO 7730 [15]. Eqs. (1), (6) and (7) show convective $\left(Q_{\mathrm{cv}}\right)$ and radiative $\left(Q_{\text {rad,occ }}\right)$ heat loads, and moisture (HumOcc) load from occupants. Symbols are explained in Nomenclature.

$$
\begin{aligned}
& Q_{\mathrm{cv}}=f_{\mathrm{cl}} \cdot h_{\mathrm{cl}} \cdot 1.8 \cdot\left(t_{\mathrm{cl}}-t_{\mathrm{air}}\right)+1.8 \cdot 0.014 \cdot M \cdot\left(34-t_{\mathrm{air}}\right) \\
& h_{\mathrm{cl}}=2.38 \cdot\left(t_{\mathrm{cl}}-t_{\mathrm{air}}\right)^{0.25} \text { for } 2.38 \cdot\left(t_{\mathrm{cl}}-t_{\mathrm{air}}\right)^{0.25}>12.1 \sqrt{ } v_{\mathrm{air}}
\end{aligned}
$$

$h_{\mathrm{cl}}=12.1 \cdot \sqrt{ } v_{\text {air }} \quad$ for $2.38 \cdot\left(t_{\mathrm{cl}}-t_{\text {air }}\right)^{0.25}<12.1 \sqrt{ } v_{\text {air }}$

$f_{\mathrm{cl}}=1.00+1.29 \cdot I_{\mathrm{cl}} \quad$ for $I_{\mathrm{cl}}<0.078$

$f_{\mathrm{cl}}=1.05+0.645 \cdot I_{\mathrm{cl}} \quad$ for $I_{\mathrm{cl}}>0.078$

$Q_{\text {rad }, \text { occ }}=1.8 \cdot 3.96 \cdot 10^{-8} \cdot f_{\mathrm{cl}} \cdot\left(t_{\mathrm{cl}}^{4}-t_{\mathrm{mrt}}^{4}\right)$

$$
\begin{aligned}
\text { HumOcc }=1.8 \cdot( & 3.05 \cdot 10^{-3} \cdot\left(5733-6.99(M \cdot 58-W)-P_{\text {vap }}\right) \\
& +0.42((\mathrm{M} \cdot 58-\mathrm{W})-58.15)+1.7 \cdot 10^{-5} \cdot M \\
& \left.\cdot 58 \cdot\left(5867-P_{\mathrm{vap}}\right)\right) / 2501000
\end{aligned}
$$

Validation of IDA ICE 4 was performed by several studies [1721]. In IDA ICE 4 , based on the set indoor temperature all 
First floor
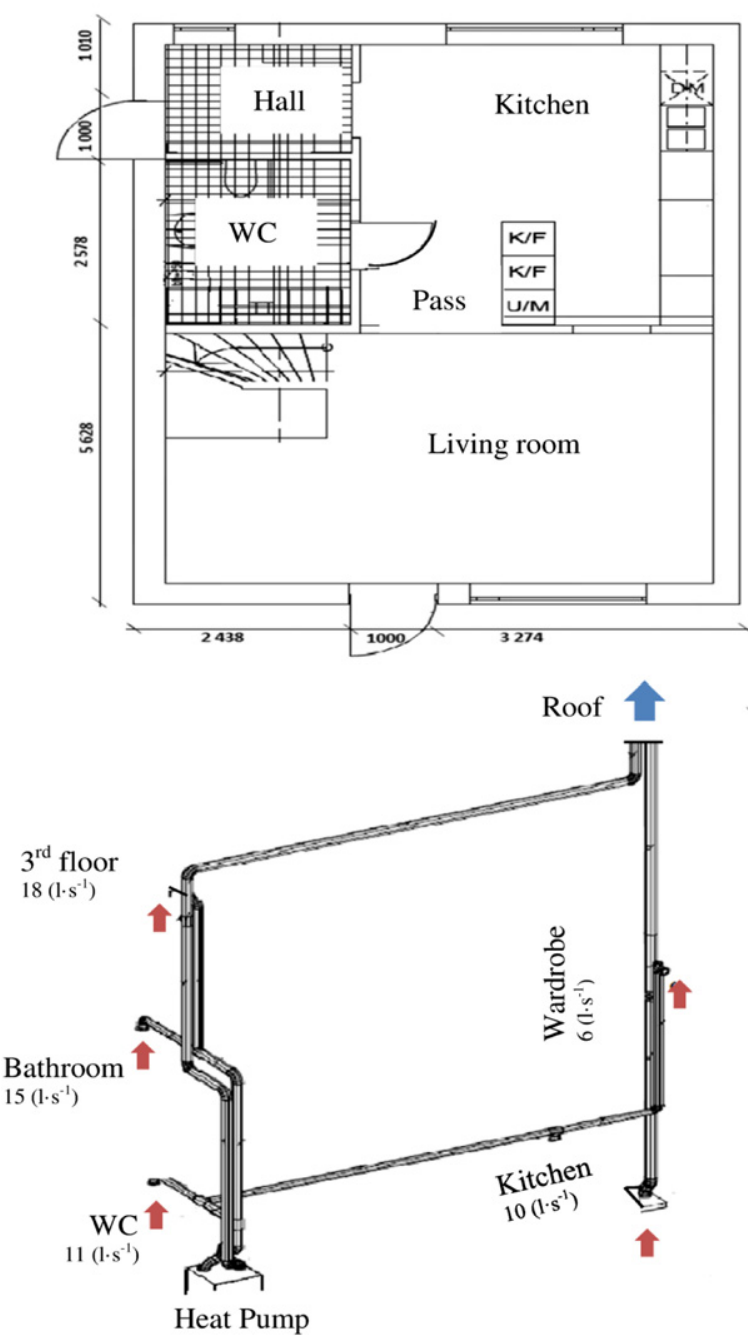

Second floor
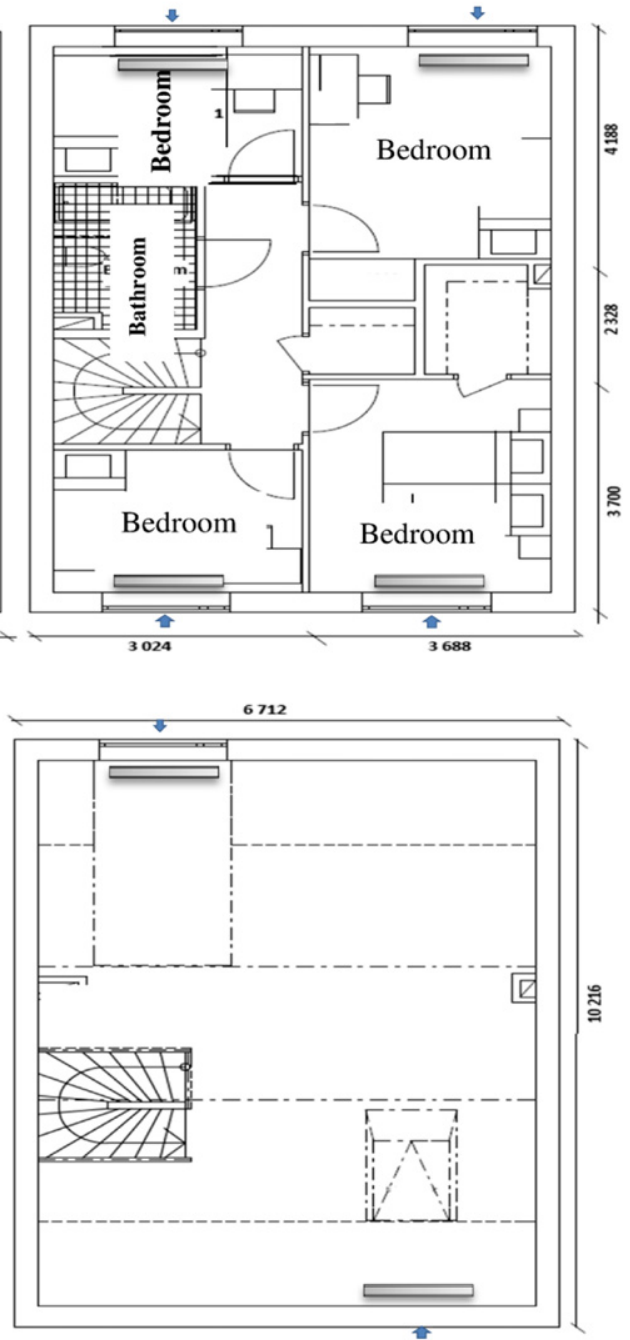

Third floor

Fig. 3. Floor plan showing the location of ventilation radiators in second and third floors and the ventilation system (values are in mm and plan is not to scale).

supplied heat and heat losses are balanced by using dynamic timesteps simulation, finite difference method and transient calculations. Heat losses depend on indoor temperature, outdoor temperature, speed and direction of wind, thermal properties of building envelopes, type of ventilation system as well as tightness and orientation of buildings. Supply heat depends on active and passive heating, i.e. internal heat (released by people based on activity level, by lightening, and by equipment) and external heat (released by solar radiation through windows). Also, the storage and emission of heat in the structure of the building, which is important for the power demand calculation, is accurately calculated in IDA ICE 4. The major drawback of using IDA ICE 4 is the risk of unexpected program crashes and also errors in creating the mathematical model during the simulation.

Table 1

$U$ value for building envelope.

\begin{tabular}{lccccll}
\hline Structure & Roof & Floor & Exterior wall & Windows & Doors & $U_{\mathrm{m}}$ \\
\hline$U$ value, $\mathrm{W} \mathrm{m}^{-2} \mathrm{~K}^{-1}$ & 0.13 & 0.15 & 0.15 & 1.10 & 1.50 & 0.28 \\
Area, $\mathrm{m}^{2}$ & 65.0 & 58.0 & 116.0 & 20.2 & 4.0 & \\
\hline
\end{tabular}

\subsubsection{Model description}

Input data including floor plan, dimension of different parts of the building and HVAC system were provided by NCC, one of leading construction and property development companies in the Nordic region. The location and size of rooms, windows and doors in the model corresponded to the real situation (Fig. 5). For more accurate results of energy consumption in simulation, each dwelling was divided into 12 zones according to usage of the rooms. For each zone a different exhaust and supply air flow rate was defined. The ground was modeled according to ISO-13370 [22] for determining the heat transfer between building and ground. In ISO13370 a $0.5 \mathrm{~m}$ layer of earth and a $0.1 \mathrm{~m}$ layer of insulation were assumed beneath the ground level floor of the buildings [23], and together with a constant ground temperature of $9{ }^{\circ} \mathrm{C}$. Also, in simulation the maximum time step was set to $1.5 \mathrm{~h}$ and the tolerance level to 0.02 . In simulation, cooling energy was not considered since there was no cooling device supplied. All dwellings were modeled with different orientation and different internal heat gain. The shading by roof overhang and neighboring buildings was considered as well. A mechanical exhaust air system with opening on external wall as supply device was defined for ventilation. 


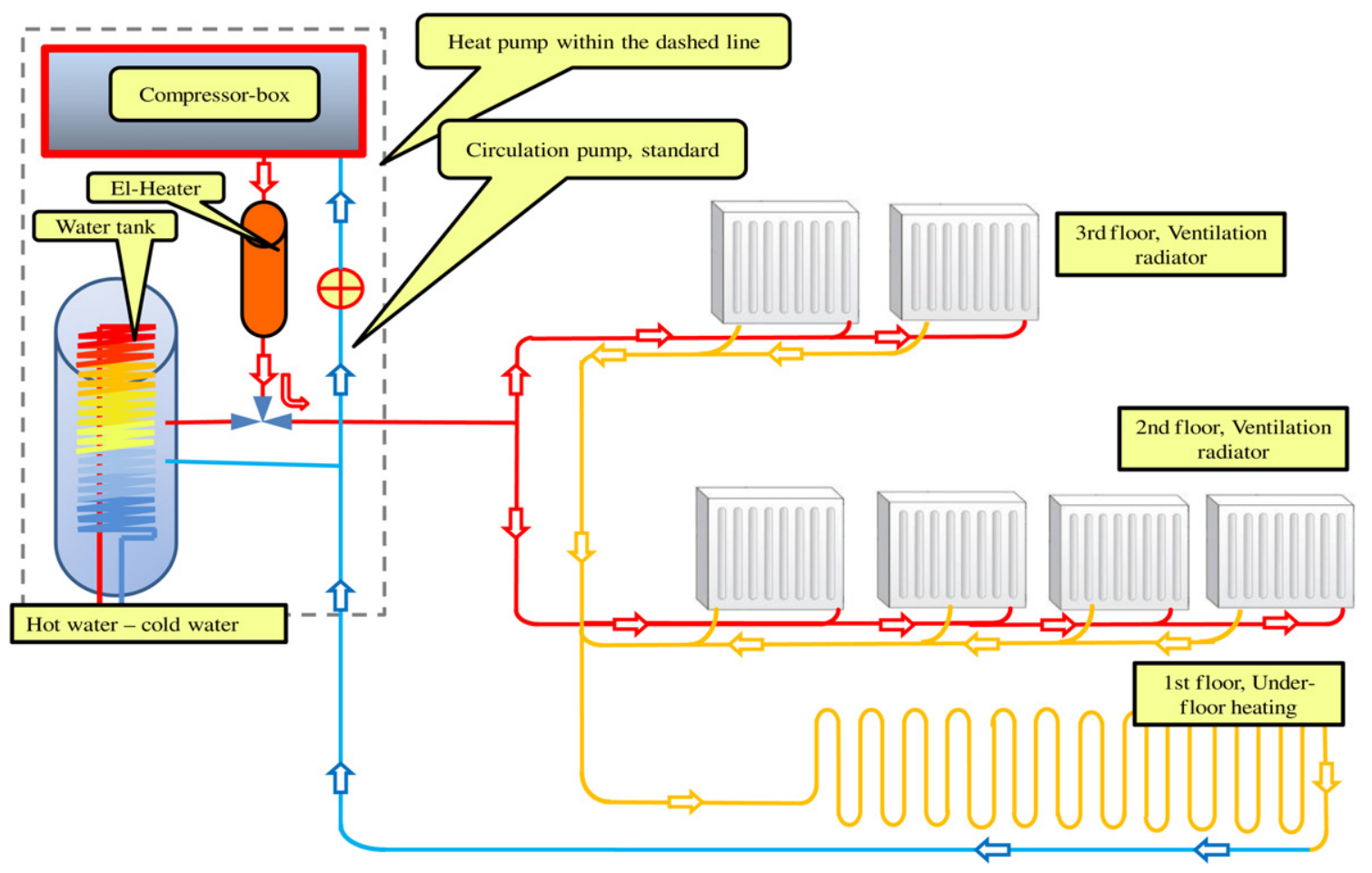

Fig. 4. Low temperature hydronic heating system connected to the heat pump.

Heating system was modeled as UFH for the first floor and radiator for the second and third floor. When modeling the radiators in IDA ICE 4, the maximum heat output as well as the supply and return temperature to the radiator were set equal to the corresponding values of the ventilation radiator. The maximum power of ventilation radiator was achieved by an Excel-based program called AIRSimulator. The heat output given by this program is validated experimentally for the different applications used.

The heat pump was modeled as boiler with an average constant electric COP of 2.7 over the year, since it was not possible to set up a variable COP function for a heat pump in IDA ICE 4. This assumption seems reasonable since the temperature of heat source (room temperature) or evaporation temperature is constant over the year in an exhaust air heat pump.

The value 2.7 was obtained from Ref. [13] giving a mean COP for exhaust air heat pump installations in Sweden with hot water temperature of $50{ }^{\circ} \mathrm{C}$. In IDA ICE 4 the boiler consumes energy, e.g.

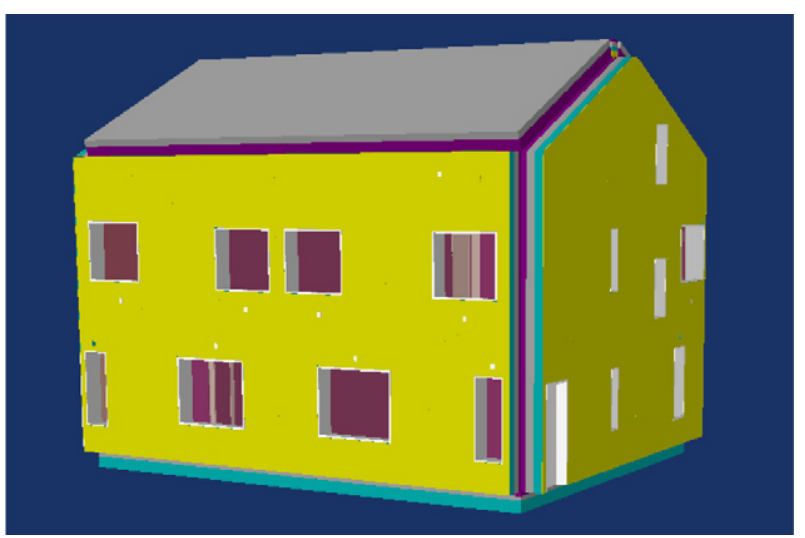

Fig. 5. Simulation of a pair of semi-detached houses using IDA ICE 4 software. gas or electricity, and produces warm water with given temperature.

To predict indirect/passive heating from people, occupants were asked to report on the number of persons living in each dwelling as well as the number of hours that they spend inside during weekdays and weekend. Responses revealed that on average, occupants spent $14 \mathrm{~h} \cdot \mathrm{day}^{-1}$ on weekdays (Fig. 6) and $20 \mathrm{~h} \cdot \mathrm{day}^{-1}$ at weekends inside the house. The contribution of each person to internal heat gain depends on the activity level, e.g. around $135 \mathrm{~W}$ heat generation in sedentary activity in living room, $150 \mathrm{~W}$ heat when eating in kitchen, and in average $85 \mathrm{~W}$ in bedrooms. In addition, to predict the contribution of lights and equipment to space heating it was assumed that the lights were on when living room and kitchen were occupied, and some equipment was running full-time in kitchen and part-time in the living room. Of the total energy consumption $760 \mathrm{~W}, 70 \%$ contributed to indirect heating [12]. DHW consumption was estimated from heat pump electricity consumption during

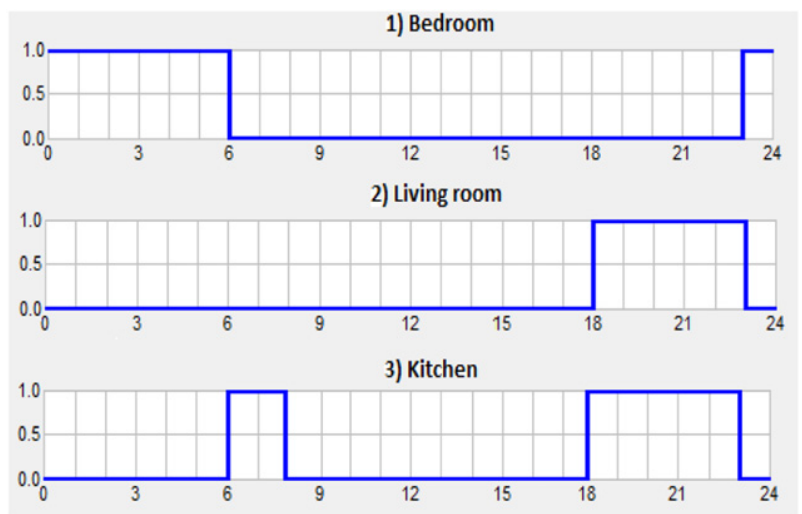

Fig. 6. Profile for the presence of the occupants on weekdays; 1 for fully occupied and 0 for absence. 
Table 2

Measurement results and mean outdoor temperature in Stockholm (SMHI 2011-2012).

\begin{tabular}{|c|c|c|c|c|c|c|c|c|c|c|c|c|c|}
\hline $\begin{array}{l}\text { Mean } \\
\text { temperature, }{ }^{\circ} \mathrm{C}\end{array}$ & Jan, -2.6 & Feb, -5.2 & Mar, 2.9 & Apr, 3.7 & May, 10.6 & Jun, 12.3 & Jul, 16.4 & Aug, 15.2 & Sep, 10.9 & Oct, 7.5 & Nov, 2.4 & Dec, 1.6 & $\begin{array}{l}\text { Total, } \\
\text { kWh m }{ }^{-2}\end{array}$ \\
\hline \multicolumn{14}{|c|}{ Energy consumption, kWh } \\
\hline 27 & 1339 & 1233 & 962 & 638 & 535 & 370 & 257 & 328 & 425 & 582 & 809 & 1231 & 54 \\
\hline 30 & 1303 & 1059 & 781 & 498 & 324 & 267 & 276 & 315 & 341 & 570 & 891 & 1146 & 49 \\
\hline 31 & 1367 & 973 & 763 & 621 & 431 & 291 & 232 & 278 & 420 & 648 & 996 & 1208 & 51 \\
\hline 32 & 1308 & 906 & 731 & 594 & 409 & 286 & 248 & 237 & 339 & 564 & 886 & 1130 & 48 \\
\hline 33 & 1478 & 1127 & 716 & 453 & 468 & 352 & 260 & 281 & 407 & 657 & 1162 & 1320 & 54 \\
\hline
\end{tabular}

summer months, since the only reason that the heat pump provides heating is because of DHW consumption in this period. A natural variation in DHW consumption between buildings was observed, probably depending on different living habits.

\subsection{Site measurements}

For site measurements occupants of the five houses were asked to read and report heat pump electricity consumption each month. This consumption was used for space heating, hot water and ventilation. The buildings were occupied on 14th December 2011. The starting point for the measurements was thus 14th December 2011, and the last reported value for this study was on 13th December 2012.

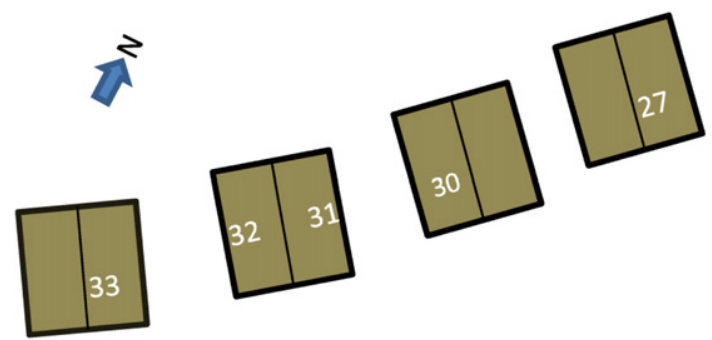

Fig. 7. Orientation of the five dwellings studied.

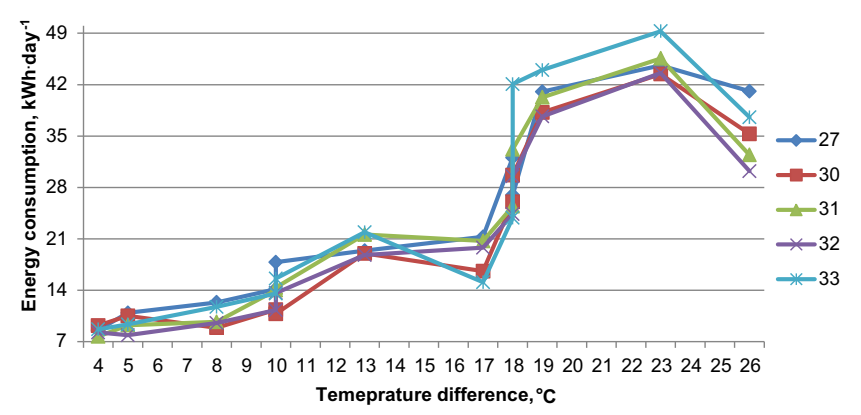

Fig. 8. Heating load as a function of temperature difference between inside and outside for the five dwellings.

\subsection{Thermal comfort analysis}

The buildings studied have a high level of airtightness and are well-insulated, so there is a high potential for achieving acceptable indoor climate [24]. IDA ICE software uses the ISO 7730 [25] assessment method to determine the comfort level achieved. The thermal comfort supplied by the model took account of the PMV related PPD value [26] and mean radiant and operative temperature at the given average wind velocity. Thermal comfort analyses and PPD calculations in IDA ICE are based on Fanger's models [27] and a simple model for linear vertical temperature gradient is used [28].

More detailed analyzes of thermal comfort with ventilation radiator is given in reference [11]. In this work, Myhren and Holmberg analyzed both ventilation and conventional radiators regarding their heat output and thermal comfort using CFD modeling. Simulation showed that ventilation radiator gives a more favorable, i.e. stable thermal climate. Also, their results of CFD modeling showed that the risk of cold draught was reduced when using ventilation radiator. In current study, to survey the thermal comfort in reality a questionnaire was distributed to occupants. In the questionnaire they were asked how satisfied they were with the temperature and air quality in different rooms and if they feel any discomfort with respect to draught.

\section{Results}

\subsection{Measurements result (December 2011-December 2012)}

Measurements included electricity consumed by heat pump with integrated fan used for space heating, domestic hot water and ventilation. The annual total electricity used by the heat pump from December 2011 to December 2012 for different houses is presented in Table 2. As can be seen, although all dwellings are constructed the same, electricity consumption varied for different dwellings due to different internal loads, living habits, orientation of buildings and shading effects of surrounding buildings. Fig. 8 shows the space heating load for the houses as a function of temperature difference between inside $\left(21.0^{\circ} \mathrm{C}\right)$, and mean outside temperature shown in Table 2, In February the temperature difference $\left(26.2{ }^{\circ} \mathrm{C}\right)$ was higher than in January $\left(23.6{ }^{\circ} \mathrm{C}\right)$, but the heating demand in February was less than in January, as shown in Fig. 8. A higher intensity of solar radiation in February is a likely reason for this, but

Table 3

Simulation results of energy consumption by IDA ICE 4 for different rooms and equipment from December 2011 to December 2012.

\begin{tabular}{|c|c|c|c|c|c|c|c|c|c|c|c|c|c|c|c|}
\hline \multicolumn{2}{|c|}{ Total, kWh m ${ }^{-2}$} & \multicolumn{2}{|c|}{ Living room (UFH) } & \multicolumn{2}{|c|}{ Kitchen (UFH) } & \multicolumn{2}{|c|}{ Bedrooms (VR) } & \multicolumn{2}{|c|}{ Bathroom, WC (UFH) } & \multicolumn{2}{|c|}{ Third floor (VR) } & \multicolumn{2}{|c|}{ Hot water } & \multicolumn{2}{|l|}{$\mathrm{AHU}$} \\
\hline & & $\mathrm{kWh}$ & $\%$ & kWh & $\%$ & kWh & $\%$ & kWh & $\%$ & kWh & $\%$ & kWh & $\%$ & $\mathrm{kWh}$ & $\%$ \\
\hline 27 & 55 & 1605 & 18 & 144 & 2 & 1683 & 19 & 287 & 3 & 1104 & 13 & 3520 & 40 & 480 & 5 \\
\hline 30 & 53 & 1483 & 17 & 161 & 2 & 1686 & 20 & 305 & 4 & 1097 & 13 & 3360 & 39 & 480 & 6 \\
\hline 31 & 52 & 1494 & 18 & 133 & 2 & 1588 & 19 & 252 & 3 & 1141 & 14 & 3200 & 39 & 480 & 6 \\
\hline 32 & 51 & 1634 & 20 & 133 & 2 & 1659 & 20 & 251 & 3 & 1102 & 13 & 3040 & 37 & 480 & 6 \\
\hline 33 & 55 & 1660 & 19 & 162 & 2 & 1717 & 19 & 252 & 3 & 1167 & 13 & 3520 & 39 & 480 & 5 \\
\hline
\end{tabular}


Table 4

Details of annual mean passive heat and heat losses for different dwellings between December 2011 and December 2012, according to the IDA ICE 4 simulation.

\begin{tabular}{|c|c|c|c|c|c|}
\hline & 27 & 30 & 31 & 32 & 33 \\
\hline No of persons & 4 & 4 & 5 & 3 & 3 \\
\hline Mean transmission loss, $\mathrm{W}$ & -804 & -852 & -849 & -822 & -814 \\
\hline Mean ventilation loss, $\mathrm{W}$ & -1174 & -1323 & -1283 & -1298 & -1193 \\
\hline $\begin{array}{l}\text { Mean internal heat gain } \\
\text { from occupants, } \mathrm{W}\end{array}$ & 473 & 473 & 591 & 355 & 355 \\
\hline $\begin{array}{l}\text { Mean internal heat gain } \\
\text { from equipment, } \mathrm{W}\end{array}$ & 390 & 390 & 390 & 390 & 390 \\
\hline $\begin{array}{l}\text { Mean internal heat gain } \\
\text { from lights, } W\end{array}$ & 143 & 143 & 143 & 143 & 143 \\
\hline $\begin{array}{l}\text { Mean external heat gain } \\
\quad \text { from solar radiation, } \mathrm{W}\end{array}$ & 468 & 643 & 477 & 693 & 569 \\
\hline Passive heat gain/heat loss, $\%$ & 75 & 76 & 75 & 75 & 73 \\
\hline
\end{tabular}

also living habits and building orientation may influence. The average total solar radiation towards a vertical surface facing south in Stockholm [SMHI] is $25 \mathrm{kWh} \mathrm{m}^{-2}$ in January and $50 \mathrm{kWh} \mathrm{m}^{-2}$ in February.

\subsection{Simulation result (December 2011-December 2012)}

Energy use analyses carried out by IDA ICE 4 included the effect of heat capacity, infiltration, internal and external heat gain, weather data, indoor temperature and detail description of the construction type and building geometry. IDA ICE 4 simulation was run for five different houses taking account of their orientation (Fig. 7) and internal heat gain during 14th December 2011 till 13th December 2012 (one year). The results of total consumption and required space heating based on the usage of the room are given in Table 3. As can be seen, heating demand in the kitchen was much less than for other parts of the house, due to more internal heat gain from installations. Also, energy consumption for DHW depends on the living habit and it differed for each dwelling.

Table 4 illustrates a detailed expression of annual mean passive heat gain and ventilation and transmission losses for each dwelling. The internal heat gain from people was the same for houses 27-30, and for 32-33. These groups had the same number of occupants. However, in reality the influence of internal heat gain on energy usage might be more dependent on occupant behavior than on the
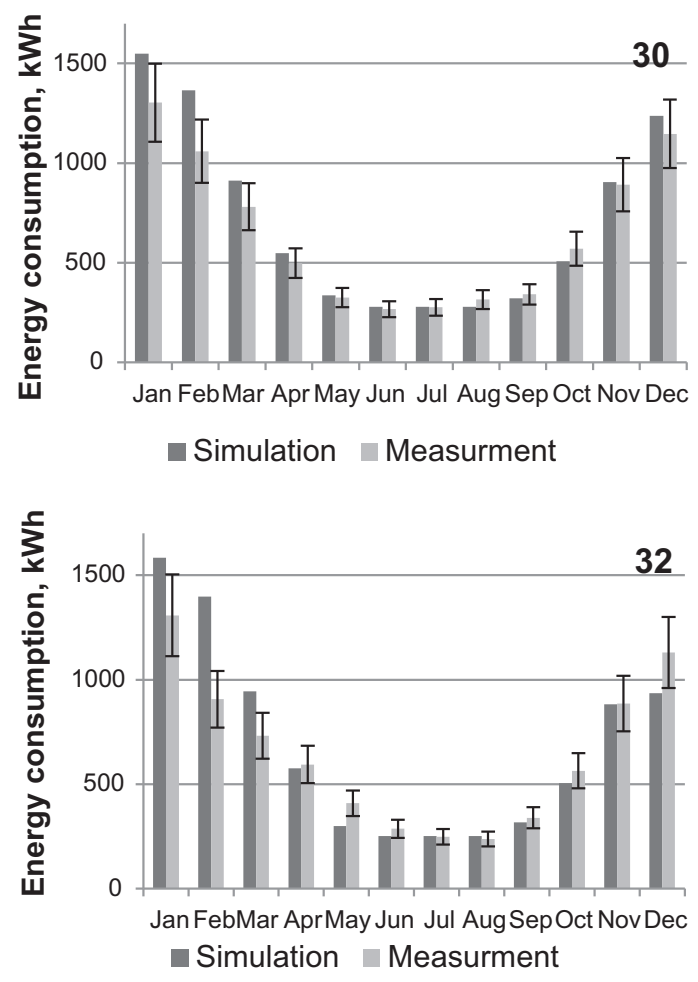

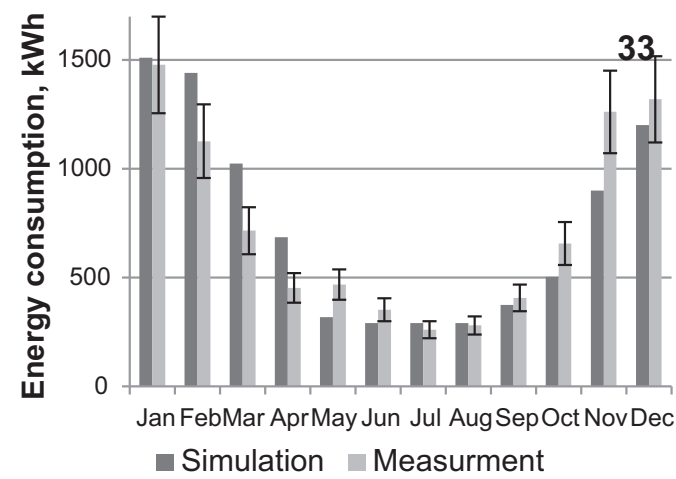

Fig. 9. Comparison of measured and calculated energy consumption in the five houses studied. 
number of persons. As shown, the external heat gain by solar radiation through windows was higher in dwellings 30 and 32 due to more southward orientation of windows. Shading by surrounding buildings and having no windows toward south resulted in low solar contribution of heat in dwellings 27 and 31, lower than in the three other buildings. However, more persons were living in this dwelling, which meant the highest passive heat gain from people. Also, an equivalent number of lights and equipment in all dwellings gave a passive heat contribution of $532 \mathrm{~W}$. The ratio of passive heat gain to heat losses in dwelling 30 was higher than in other dwellings, with dwelling 33 having the lowest value. This ratio shows how the total passive heating, i.e. number of occupants, solar gain due to orientation of building, etc. in different buildings influence the total heating demands.

\subsection{Model validation: measurements vs. simulation}

The IDA ICE model was experimentally validated by comparing the results of simulation with site measurements, see Fig. 9. The error bar in Fig. 9 is in a range of $15 \%$ deviation of measured value. There appeared to be a good agreement between simulation results and measurements, i.e. for most months the simulation results are in range of $15 \%$ deviation of measured value. However, the simulation sometimes overestimated/underestimated the heating demand. Some possible reasons for that could be slight difference in the ventilation radiator shape and different defined living habit in the simulation compared to reality. A possible explanation for the rather large deviation in February compared to other months can be explained by high solar radiation intensity; providing preheating of ventilation air and decreasing the space heating load, which may not be predicted in simulation. A comparison of total consumption in simulation and measurements (Fig. 10) shows that the total values are very close to each other, with a maximum deviation of $7 \%$ for house 30 . Hence, with help of this validation it can be concluded that the simulation results are in good agreement with the real heating demand.

According to the Swedish building regulations [12], depending on location and heating source, all houses should meet energy guidelines for heating, ventilation, cooling and hot water. Table 5 shows the maximum allowable of energy requirement depending on climate zone. Sweden has three climate zones, north "1", middle " 2 " and south " 3 "; Stockholm is located in climate zone 3 .

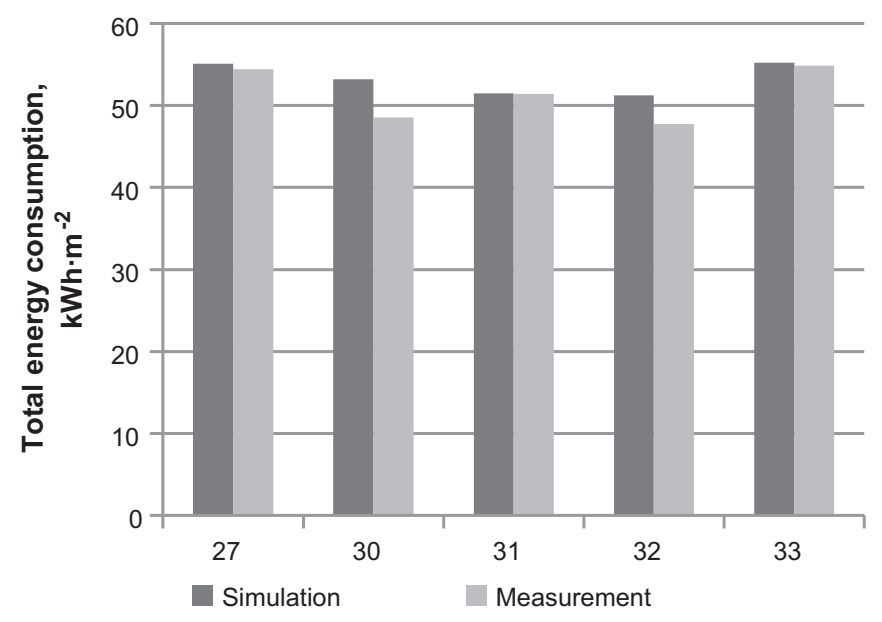

Fig. 10. Comparison of total consumption between measurement and simulation in the five houses studied.
Table 5

Swedish energy requirement [12].

\begin{tabular}{llll}
\hline Climate zone & 1 & 2 & 3 \\
\hline $\begin{array}{c}\text { Building heated by other means than electricity: } \\
\begin{array}{c}\text { total energy consumption, kWh m } \\
\text { Building per year } \\
\text { total energy consumption, } \mathrm{kWh} \mathrm{m}^{-2} \text { per year }\end{array}\end{array}$ & 150 & 130 & 110 \\
\hline
\end{tabular}

Looking at the energy requirement of the dwellings in Table 5, all investigated buildings satisfy the maximum required energy consumption, i.e. $55 \mathrm{kWh} \mathrm{m}^{-2}$ per year.

\subsection{Thermal comfort results}

IDA ICE simulation showed that the PMV-based PPD is $12 \%$. This is acceptable and thus lower than the (EN ISO 7730) standard regulation of $15 \%$. The simulation also showed that the mean temperature level in all zones varied within $20^{\circ} \mathrm{C}$ and $25^{\circ} \mathrm{C}$, which also fulfill standard regulations.

In the questionnaire some occupants reported cold draught on the first floor, where fresh air was directly brought into the house without preheating. This was not the case on the second and third floors, where ventilation radiators were installed. These reports can be explained by the slow reaction of UFH (large thermal mass flow of water) on the first floor, causing higher temperature fluctuations [29], so that occupants may feel cold before the system has reached stable conditions. Generally, all occupants were satisfied with the mean temperature in their dwelling.

\section{Conclusion}

The purpose of the study was to ascertain whether it is possible to have low temperature heating systems that meet energy requirements without compromising thermal comfort. Hence, dwellings equipped with LTHH systems were evaluated in terms of energy consumption and thermal comfort. The energy consumption for space heating, ventilation and hot water determined by IDA ICE simulation approximately corresponded to on-site measurements with small divergence. Looking at energy requirements and Swedish building regulations, the paper concludes that the dwellings equipped with LTHH system can meet limitation of energy consumption. Investigation of thermal comfort was also made, both by using IDA ICE software and by questionnaire. Simulations showed that the PMV based PPD was $12 \%$, and mean temperature variation in all zones was in acceptable range. Also, the questionnaire showed that occupants felt more comfortable in floors equipped with ventilation radiators compared to the ground floor with under-floor heating. It should be noted, however, that this study was of five dwellings only; future study of other types and greater number of dwellings are needed before it is possible to generalize regarding all houses using low temperature heating systems.

\section{Acknowledgement}

We are grateful to the Swedish Energy Agency (Energimyndigheten) and SBUF, The Development Fund of the Swedish Construction Industry for financial support. We also wish to thank Nina Forsberg from the NCC construction and property development company in Nordic region for her unsparing help as well as our colleagues Jonn Are Myhren and Adnan Ploskic for their ample support and praiseworthy effort in this relatively new area of research. 


\section{References}

[1] Tommerup H, Rose J, Svendsen S. Energy-efficient houses built according to the energy performance requirements introduced in Denmark in 2006. Energy and Buildings 2007;39:1123-30.

[2] Anisimova N. The capability to reduce primary energy demand in EU housing. Energy and Buildings 2011;43:2747-51.

[3] Myhren JA, Holmberg S. Flow patterns and thermal comfort in a room with panel, floor and wall heating. Energy and Buildings 2008;40:524-36.

[4] Ploskic A. Low-temperature baseboard heaters in built enviroments. Stockholm-Sweden: Licentiate Thesis in Civil and Architectural Engineering: KTH Royal Institute of Technology; 2010.

[5] Holmberg S, Myhren JA, Ploskic A. Low-temperature heat emission with integrated ventilation air supply. In: Proceedings of CLIMA 10, Antalya, Turkey, 2010.

[6] Myhren JA, Holmberg S. Energy savings and thermal comfort with ventilation radiators - a dynamic heating and ventilation system. In: Proceedings of CLIMA 7, Helsinki, Finland, 2007.

[7] Olesen BW, Mortensen E, Thorshauge J, Berg-Munch B. Thermal comfort in a room heated by different methods, ASHRAE Transactions Technical paper no. 2256, 1980, 86pp..

[8] Hutter E. Comparison of different heat emitters in respect of thermal comfort and energy consumption. In: Proceedings of the international center for heat and mass transfer, heat and mass transfer in building materials and structures, 1991, p. 753-769.

[9] Myhren JA. Potential of Ventilation Radiators: performance evaluation by numerical, analytical and experimental investigations. Stockholm, Sweden: Doctoral Thesis in Civil and Architectural Engineering; KTH Royal Institute of Technology, 2011.

[10] Ploskic A, Holmberg S. Low-temperature baseboard heaters with integrated air supply - an analytical and numerical investigation. Building and Environment 2011;46:176-86.

[11] Myhren JA, Holmberg S. Design consideration with ventilation-radiators: comparisons to traditional two-panel radiators. Energy and Buildings 2009;41:92-100.

[12] http://www.boverket.se/.

[13] Nowacki JE. Heat pumps in energy statistics - suggestions. [Online], http:// www.ssb.no/ocg/vienna/8a_paper.pdf; 2007.

[14] Jokisalo J. On design principles and calculation methods related to energy performance of building in Finland. Finland: Doctoral Thesis, Helsinki University of Technology; 2008.
[15] Bring A, Sahlin P, Vuolle M. Models for building indoor climate and energy simulation. Stockholm: Dept. of Building Sciences, KTH; 1999. A report of IEA SHC task 22.

[16] Vuolle M, Bring A, Sahlin P. An NMF based model library for building thermal simulation. In: Proceedings of building simulation, Kyoto, Japan; 1999.

[17] Travesi J, Maxwell G, Klaassen C, Holtz M. Empirical validation of Iowa energy resource station building energy analysis simulation models 2001.

[18] Validation of IDA indoor climate and energy 4.0 with respect to CEN standards EN 15255-2007 and EN 15265-2007 2010

[19] Validation of IDA indoor climate and energy 4.0 build 4 with respect to ANSI/ ASHRAE standard 140-2004 2010.

[20] Moosberger S. IDA ICE CIBSE-validation: test of IDA indoor climate and energy version 4.0 according to CIBSE TM33, issue 3. SAP-Nr.: 11202132007.

[21] Kropf S, Zweifel G. Validation of the building simulation program IDA-ICE according to CEN 13791 "Thermal performance of buildings - calculation of internal temperatures of a room in summer without mechanical cooling general criteria and validation procedures".

[22] ISO-13370. Thermal performance of buildings, heat transfer via ground, calculation methods 1998 .

[23] Bambrook SM, Sproul A, Jacob D. Design optimisation for a low energy home in Sydney. Energy and Buildings 2011;43:1702-11.

[24] Molin A, Rohdin P, Moshfegh B. Investigation of energy performance of newly built low-energy buildings in Sweden. Energy and Buildings 2011;43: $2822-31$.

[25] ISO 7730. Ergonomics of the thermal environment - Analytical determination and interpretation of thermal comfort using calculation of the PMV and PPD indices and local thermal comfort criteria 2005.

[26] ASHRAE ANSI/ASHRAE Standard 55-2004. Thermal environmental conditions for human occupancy. Atlanta: American Society of Heating, Refrigerating, and Air-conditioning Engineers, Inc.; 2004.

[27] Fanger PO, Christensen NK. Perception of draught in ventilated space. J Ergon 1986;29:215-35.

[28] Sahlin P, Eriksson L, Grozman P, Johnsson H, Shapovalov A, Vuolle M. Will equation-based building simulation make it? Experiences from the introduction of IDA indoor climate and energy. In: Proceeding of 8th international IBPSA conference, Netherland, 2003. Netherland, 2003.

[29] Hasan A, Kurnitski J, Jokiranta K. A combined low temperature water heating system consisting of radiators and floor heating. Energy and Buildings 2009;41: 470-9. 